\title{
Unusual complement of three AKH octapeptides in two species of grasshoppers (Caelifera)
}

\author{
GERD GÄDE \\ Zoology Department, University of Cape Town, Rondebosch 7701, South Africa; e-mail: ggade@botzoo.uct.ac.za
}

\begin{abstract}
Key words. Caelifera, Lamarckiana sparrmani, Pamphagidae, Zonocerus elegans, Pyrgomorphidae, adipokinetic peptide, peptide sequencing, Edman sequencing, fast atom bombardment mass spectrometry, octapeptides
\end{abstract}

\begin{abstract}
The corpora cardiaca (CC) of the two grasshopper species Zonocerus elegans (Pyrgomorphidae) and Lamarckiana sparrmani (Pamphagidae) contain (a) substance(s) that cause(s) hyperlipaemia in the migratory locust and hypertrehalosaemia in the American cockroach. Isolation of neuropeptides belonging to the adipokinetic hormone (AKH) family was achieved by single-step reversed-phase high performance liquid chromatography of CC extracts from both species and monitoring tryptophan fluorescence. The material of both species showed three distinct fluorescence peaks with adipokinetic activity in the migratory locust. The peptides were identifid by at least two of the following methods: (1) sequencing by Edman degradation, (2) sequencing by tandem fast atom bombardment mass spectrometry, (3) mass determination by matrix-assisted laser desorption/ionisation time-of-flight mass spectrometry and (4) co-elution of the native and synthetic peptides. Both species were found to have three AKH peptides stored in the $\mathrm{CC}$, but unlike in other grasshoppers, none of those peptides were decapeptides. In Z. elegans the following three octapeptides occur: Schgr-AKH-II (pELNFSTGWamide), Peram-CAH-II (pELTFTPNWamide) and Phymo-AKH-III (pEINFTPWWamide), whereas L. sparrmani contains the octapeptides Grybi-AKH (pEVNFSTGWamide), Pyrap-AKH (pELNFTPNWamide) and also Phymo-AKH-III. Conspecific bioassays show no adipokinetic and only a weak (not significant) hypertrehalosaemic effect (in the pamphagid grasshopper). Some explanations are offered on the possible role of these peptides in the species investigated by interpreting their life style.
\end{abstract}

\section{INTRODUCTION}

When energy demands for locomotory or reproductive activity outpace the small amount of high-energy phosphates (ATP, arginine phosphate) and metabolites that are readily accessible in muscles and haemolymph, stored reserves in the fat body have to be mobilised. This mobilisation of potential fuels of various classes (lipids, carbohydrates, amino acids, such as proline) is hormonally controlled in insects by small neuropeptides of the socalled adipokinetic hormone $(\mathrm{AKH}) /$ red pigmentconcentrating hormone (RPCH) family (Gäde, 2004). The peptides are synthesised and stored in neurosecretory cells of the retrocerebral corpora cardiaca (CC). Structurally, members of the AKH family are octa-, nona- or decapeptides which are characterised by a N-terminus blocked by a pyroglutamate residue, a C-terminus that is also blocked and contains an amide, aromatic residues at positions 4 (phenylalanine or tyrosine) and 8 (always tryptophan), and a glycine residue at position 9 (Gäde, 1996; Gäde et al., 1997). The first decapeptide member of the AKH family, which is today denoted as LocmiAKH-I, was reported present in Caelifera, i.e. in the migratory and desert locusts, Locusta migratoria and Schistocerca gregaria (Stone et al., 1976). Genus-specific octapeptides are also present as AKHs in these species and these are denoted as Locmi-AKH-II and SchgrAKH-II, respectively (Siegert et al., 1985; Gäde et al., 1986); interestingly, however, only the migratory locust contains a further octapeptide, Locmi-AKH-III (Oudejans et al., 1991). About a decade later, two additional genera of Caelifera were found to synthesise three AKH peptides and, again, structurally it was one decapeptide and two octapeptides (Siegert et al., 2000). During an ongoing project to characterise peptides of the AKH family and interpret their primary structures in an evolutionary context (Gäde et al., 2003; Gäde \& Marco, 2005), two species of grasshoppers from different families were analysed. I report here that these grasshoppers which belong to the families of Pyrgomorphidae and Pamphagidae, respectively, contain a unique complement of $\mathrm{AKH}$ peptides in their CC, namely octapeptides only.

\section{MATERIAL AND METHODS}

\section{Insects}

About 80 adult specimens of both sexes of the pyrgomorphid grasshopper Zonocerus elegans (Thunberg, 1815) were collected in the austral summer (February 1992) in the Northern Cape Province of South Africa close to the former Kalahari Gemsbok Park (now called Kgalagadi Transfrontier Park). Male adult specimens of the pamphagid grasshopper Lamarckiana sparrmani (Stål, 1876) were collected during the austral summers of 1992 (February), 1993 and 1994 (December) either close to the Kalahari Gemsbok Park or in the Karoo in the vicinity of Beaufort West. L. sparrmani is never abundant and on a single collecting trip, only a few male specimens were collected at dusk or early evening when collectors were alerted by their calls. Corpora cardiaca were immediately dissected on the day of collection and were kept in $80 \%$ methanol at $4^{\circ} \mathrm{C}$ until extraction. Some grasshoppers were kept in our insectary in Cape Town for a few days in order to perform biological assays (see below). For heterologous bioassays adult male migratory locusts, Locusta migratoria, and adult male American cockroaches, Periplaneta americana, were used; their rearing is outlined elsewhere (Gäde, 1991a). 


\section{Isolation of neuropeptides and structural analyses}

Methanolic extracts of $\mathrm{CC}$ were prepared as described previously (Gäde et al., 1984). The dried material was either taken up in water for bioassaying (see below) or it was dissolved in $15 \%$ acetonitrile containing $0.1 \%$ trifluoroacetic acid (TFA) for reversed-phase high performance liquid chromatography (RPHPLC) using columns and equipment as described previously (Gäde, 1985; see also legend to Fig. 1).

Biological activity of HPLC-derived fractions was determined in a heterologous bioassay (in the migratory locust). Biologically active material from such HPLC separations was then digested with pyroglutamate aminopeptidase (Gäde et al., 1988), and the resulting mixture of digested and undigested peptides was subsequently separated by RP-HPLC (as above, but using a gradient from 33 to $53 \% \mathrm{~B}$ within $40 \mathrm{~min}$ ). The deblocked peptide was subjected to automated Edman degradation using a model 477A sequencer connected to an on-line model 120 phenylhydantoin amino acid analyser (Applied Biosystems, Foster City, CA, USA).

Biologically active fractions were also analysed by mass spectrometry using a matrix-assisted laser desorption/ionisation time-of-flight (MALDI-TOF) instrument (Voyager-DE ${ }^{T M}$ PRO Biometry Workstation from Applied Biosystems, Inc., Framingham, MA, USA). Samples were prepared in alpha-cyano-4hydroxycinnamic acid, and spectra were acquired in positive, linear mode. Some biologically active fractions were also analysed by fast atom bombardment mass spectrometry (FAB-MS). Materials were subjected to collision-induced dissociation tandem FAB-MS using a VG 70 SE 4F instrument; helium was used as collision gas, and the collision cell was held at $4 \mathrm{kV}$.

\section{Bioassays}

The bioassays in locusts and cockroaches were performed as described previously (Gäde, 1980). Bioassays with the two grasshopper species under study were performed as with the locust. Lipids and carbohydrates in the haemolymph were quantified as vanillin-positive (Zöllner \& Kirsch, 1962) and anthrone-positive (Spik \& Montreuil, 1964) material, respectively.

Qualitative analysis of oligosaccharides in the haemolymph of $Z$. elegans was achieved by isocratic HPLC on an aminophase support and detection using a refractive index monitor as outlined previously (Gäde, 1991b).

\section{Synthetic peptides}

Synthetic peptides Grybi-AKH, Locmi-AKH-I, SchgrAKH-II, Peram-CAH-I and II, Phymo-AKH-III and Pyrap-AKH were either purchased from Peninsula Laboratories (Belmont,
CA, USA) or were custom-synthesised by solid-phase chemistry by Dr R. Kellner (Merck KGaA, Darmstadt).

\section{RESULTS AND DISCUSSION}

\section{Presence of adipokinetic neuropeptide material}

A crude methanolic extract of 0.1 pair equivalent of a $\mathrm{CC}$ extract from $Z$. elegans had lipid-mobilising activity in locusts, as well as carbohydrate-mobilising activity in cockroaches (Table 1). Compared with the maximal possible response for lipid release in locusts, which was achieved by injecting $10 \mathrm{pmol}$ of the endogenous peptide Locmi-AKH-I, the increase after injection of the Z. elegans extract amounted to almost $60 \%$. In cockroaches, such an extract was as active as $10 \mathrm{pmol}$ of the endogenous peptide Peram-CAH-I. The total vanillin-positive material in the haemolymph of $Z$. elegans was much lower than in the locust and no increase of circulating lipids was caused by injection of 0.1 pair equivalent of endogenous material (Table 2). Conversely, the total anthrone-positive material in the haemolymph of $Z$. elegans was very high, but, again, no significant effect on this concentration was elicited by injection of endogenous gland material (Table 2).

For the pamphagid grasshopper, L. sparrmani, mostly heterologous bioassays were performed due to the low number of specimens available for bioassays. In both test insects, locusts and cockroaches, 0.1 pair equivalent of the pamphagid $\mathrm{CC}$ material was active in mobilising lipids and carbohydrates, respectively (Table 1). These effects were about $75 \%$ of the respective maximal responses.

Thus, this first series of experiments have established that (a) both species under investigation contain one or more substances in their CC that appear to control metabolite levels, a function attributed to members of the AKH family of peptides and (b) that, at least in the pyrgomorphid species, the endogenous material in the $\mathrm{CC}$ has no obvious effect in mobilisation of substrates when conspecifically injected.

\section{Peptide purification, characterisation and conformation}

Typical chromatograms resulting from RP-HPLC fractionation of a methanolic extract from 2 pair equivalents

TABLE 1. Adipokinetic activity of a crude methanolic extract of corpora cardiaca from the grasshoppers Zonocerus elegans and Lamarckiana sparrmani.

\begin{tabular}{|c|c|c|c|c|c|c|c|c|c|c|}
\hline \multirow{2}{*}{$\begin{array}{l}\text { Acceptor insect } \\
\text { Treatment }\end{array}$} & \multicolumn{4}{|c|}{$\begin{array}{c}\text { Locusta migratoria } \\
\text { Haemolymph lipids }\left(\mathrm{mg} \mathrm{m}^{-1}\right)\end{array}$} & \multicolumn{6}{|c|}{$\begin{array}{c}\text { Periplaneta americana } \\
\text { Haemolymph carbohydrates }\left(\mathrm{mg} \mathrm{ml}^{-1}\right)\end{array}$} \\
\hline & $\mathrm{n}$ & $0 \mathrm{~min}$ & $90 \mathrm{~min}$ & Difference & $\mathrm{P}^{*}$ & $\mathrm{n}$ & $0 \mathrm{~min}$ & $90 \min$ & Difference & $\mathrm{P}^{*}$ \\
\hline Control (10 $\mu 1$ distilled water) & 6 & $11.5 \pm 1.7$ & $11.9 \pm 2.1$ & $0.4 \pm 1.5$ & - & 7 & $16.8 \pm 3.9$ & $18.7 \pm 4.2$ & $1.9 \pm 3.6$ & - \\
\hline $\begin{array}{l}\text { Z. elegans extract } \\
\text { ( } 0.1 \text { gland pair equivalent) }\end{array}$ & 6 & $12.8 \pm 4.1$ & $39.5 \pm 8.2$ & $26.7 \pm 6.3$ & 0.001 & 8 & $17.0 \pm 2.3$ & $41.5 \pm 7.5$ & $24.5 \pm 7.2$ & 0.001 \\
\hline $\begin{array}{l}\text { L. sparrmani extract } \\
(0.1 \text { gland pair equivalent) }\end{array}$ & 4 & $11.1 \pm 2.5$ & $47.4 \pm 6.2$ & $36.3 \pm 5.8$ & 0.001 & 4 & $16.7 \pm 3.1$ & $33.4 \pm 5.8$ & $16.7 \pm 5.4$ & 0.001 \\
\hline Locmi-AKH-I (10 pmol) & 6 & $11.8 \pm 2.2$ & $59.0 \pm 5.6$ & $47.2 \pm 6.1$ & 0.001 & - & - & - & - & - \\
\hline Peram-CAH-I (10 pmol) & & - & - & - & - & 7 & $18.7 \pm 4.5$ & $41.6 \pm 13.6$ & $22.9 \pm 8.9$ & 0.001 \\
\hline
\end{tabular}

*Students t-test was used for calculating significance of difference of treated group versus control group. 
TABLE 2. Conspecific assays for adipokinetic and hypertrehalosaemic activity.

\begin{tabular}{|c|c|c|c|c|c|c|c|c|}
\hline \multirow{2}{*}{ Treatment } & \multirow{2}{*}{$\mathrm{n}$} & \multicolumn{3}{|c|}{ Haemolymph lipids $\left(\mathrm{mg} \mathrm{ml}^{-1}\right)$} & & \multicolumn{3}{|c|}{ Haemolymph carbohydrates $\left(\mathrm{mg} \mathrm{ml}^{-1}\right)$} \\
\hline & & $0 \min$ & $90 \mathrm{~min}$ & Difference & & $0 \mathrm{~min}$ & $90 \mathrm{~min}$ & Difference \\
\hline \multicolumn{9}{|c|}{ Acceptor: Z. elegans } \\
\hline Control ( $10 \mu 1$ distilled water $)$ & 8 & $4.2 \pm 2.0$ & $4.2 \pm 1.4$ & $0.0 \pm 1.0$ & 8 & $46.7 \pm 5.8$ & $44.9 \pm 3.7$ & $-1.8 \pm 3.9$ \\
\hline Z. elegans extract ( 0.1 gland pair equivalent) & 7 & $3.1 \pm 0.6$ & $4.0 \pm 0.6$ & $0.9 \pm 0.7$ & 8 & $47.2 \pm 9.2$ & $48.0 \pm 9.4$ & $0.8 \pm 1.9$ \\
\hline \multicolumn{9}{|c|}{ Acceptor: L. sparrmani } \\
\hline Pyrap-AKH (10 pmol) & 3 & $5.4 \pm 0.4$ & $5.6 \pm 0.6$ & $0.2 \pm 0.3$ & 3 & $58.9 \pm 3.0$ & $64.0 \pm 5.3$ & $5.1 \pm 2.3$ \\
\hline
\end{tabular}

of $\mathrm{CC}$ from $Z$. elegans and one pair equivalent of $\mathrm{CC}$ from L. sparrmani are presented in Figs 1A and B (upper panels), respectively. These traces represent the fluorescence which is characteristic of the presence of the amino acid tryptophan (commonly at position 8 in all members of the AKH family of peptides). Peaks numbered I to III (Figs 1A and B, upper panels) were collected and tested for adipokinetic activity in 5 migratory locusts at a concentration of 0.1 gland equivalent. The materials with retention times of 12.2 min (peak I), 13.9 min (peak II) and $29.8 \mathrm{~min}$ (peak III) in the Z. elegans chromatogram (Fig. 1A, upper panel) and with the retention times of $11.1 \mathrm{~min}$ (peak I), $16.1 \mathrm{~min}$ (peak II) and $29.8 \mathrm{~min}$ (peak
III) for the material from L. sparrmani (Fig. 1B, upper panel) were active in causing hyperlipaemia in locusts (results not shown); such materials were selected for further analyses to elucidate their primary structure.

In Z. elegans, materials from peak I and II (representative of 40 gland equivalents) were clearly identified, after deblocking the N-terminus by pyroglutamate aminopeptidase and performing Edman degradation, as (pmoles in brackets): Peak I = Leu (28)-Asn (8)-Phe (24)-Ser (5)-Thr (4)-Gly (4)-Trp (1) and peak II = Leu (68)-Thr (31)-Phe (71)-Thr (19)-Pro (19)-Asn (11)-Trp (5). Materials from both peaks were also subjected to tandem FAB MS and the fragmentation data are shown in Figs $2 \mathrm{~A}$ and B. A
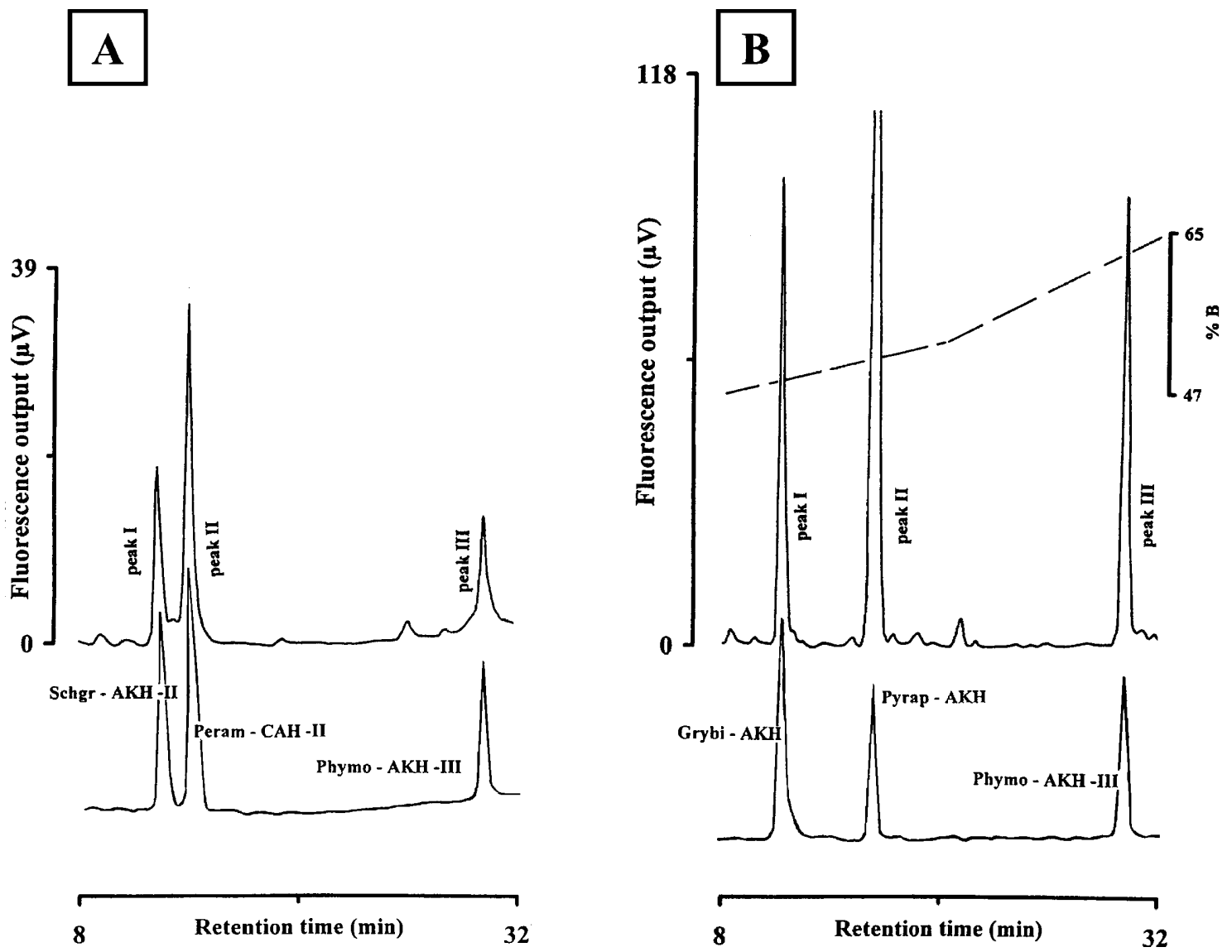

Fig. 1. Fluorescence (excitation at $276 \mathrm{~nm}$ and emission at $350 \mathrm{~nm}$ ) profiles of a methanolic extract from $\mathrm{A}$ - two pair equivalents of corpora cardiaca from Zonocerus elegans and B - one pair equivalent of corpora cardiaca from Lamarckiana sparrmani applied to a Nucleosil $100 \mathrm{C}-18$ column. The corresponding profiles of synthetic peptides run on the same day are shown below the panels A and B. A linear gradient (solvent A: $0.11 \%$ trifluoroacetic acid (TFA); solvent B: $0.1 \%$ TFA in $60 \%$ acetonitrile) was employed running from $43 \%$ to $53 \%$ B within 20 min and then from 53\% to $70 \%$ within $17 \mathrm{~min}$ at a flow rate of $1 \mathrm{ml} / \mathrm{min}$. Peak fractions numbered I to III for each species were collected and used for further studies. 


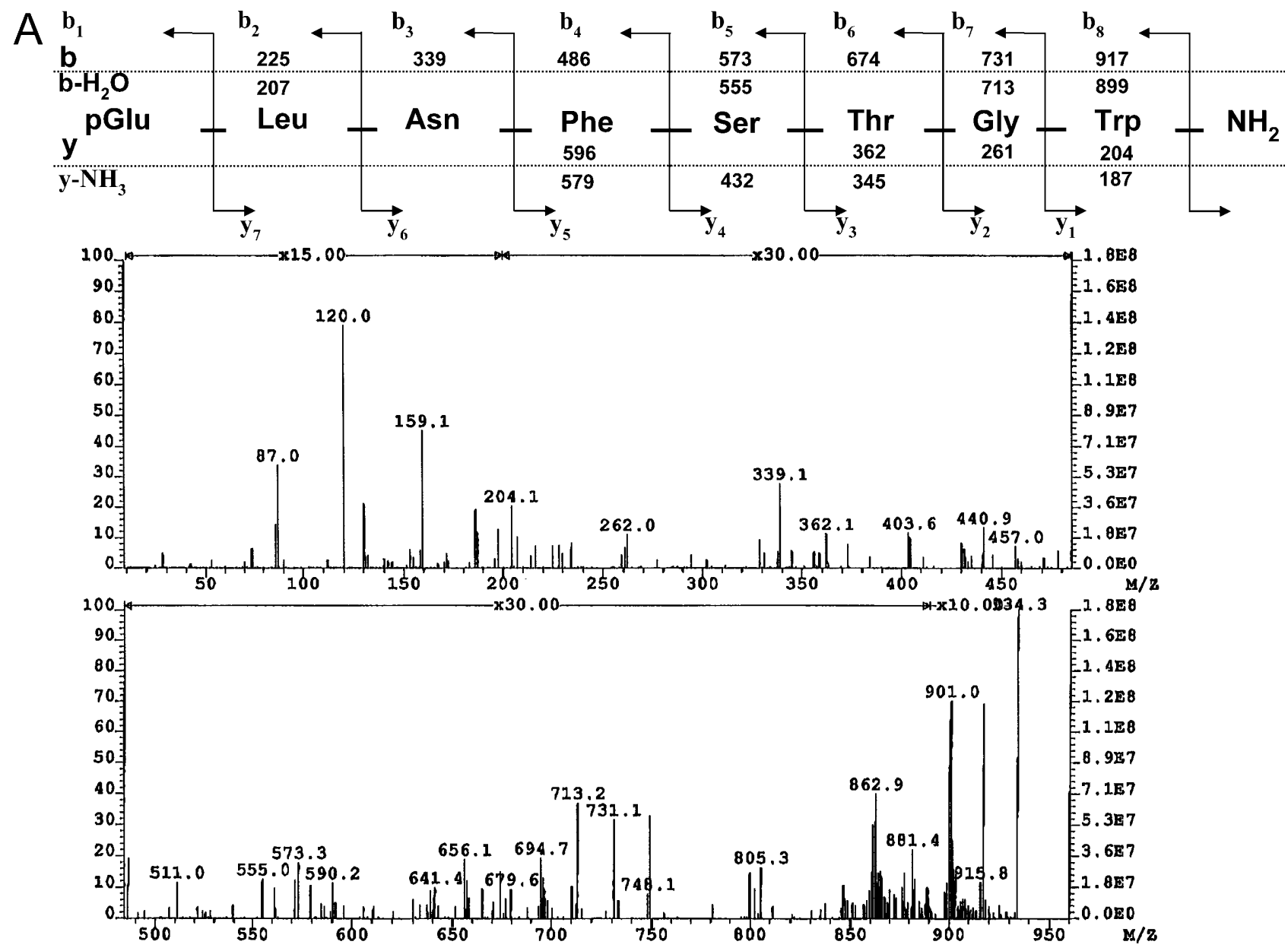

Fig. 2. Collision-induced dissociation fast atom bombardment tandem mass spectra of A - the signal of a singly charged ion at $m / z$ $=934$ (= peak I in Fig. 1A) and B - at $m / z=988$ (= peak II in Fig. 1A) of the isolated neuropeptides from Z. elegans. The top panels show the sequence as assigned by the mass spectrometric data.

number of diagnostic product ions of the $\mathrm{b}, \mathrm{b}-\mathrm{H}_{2} \mathrm{O}$, y and $\mathrm{y}-\mathrm{NH}_{3}$ series can be found (see schemes in Figs $2 \mathrm{~A}$ and B). Taken fragmentation data of such peptides (either natural or synthetic) into account, which have been published previously ( see Witten et al., 1984, Gäde \& Rinehart, 1990, for Peram-CAH-II; Gäde et al., 1986, Gäde et al., 1996 for Schgr-AKH-II), the FAB MS data support the Edman data well. Thus, the peptides were clearly identified as two well-known octapeptides, viz. SchgrAKH-II and Peram-CAH-II, respectively (see Table 3 for structures). Further confirmation came from co-elution of native and synthetic peptides as indicated in Fig. 1A (lower panel). Schgr-AKH-II and Peram-CAH-II were first discovered in the desert locust and the American cockroach (Scarborough et al., 1984; Witten et al., 1984; Siegert et al., 1985; Gäde et al., 1986). Schgr-AKH-II has since been found in a number of grasshoppers, but also in ancestral Ensifera and in Hymenoptera (Gäde, 1992; Gäde et al., 1996; Gäde \& Auerswald, 1998; Lorenz et al., 2001; Gäde et al., 2003). Peram-CAH-II is one of the typical two AKH members in blattid cockroaches, but has also been elucidated as the AKH in one species of Coleoptera (family Chrysomelidae) and one species of Hemiptera (family Pyrrhocoridae) (Gäde \& Kellner, 1989;
Kodrík et al., 2002). The third peak of Z. elegans with biological activity (peak III, see Fig. 1A, upper panel) was identified by MALDI-TOF MS revealing signals at $\mathrm{m} / \mathrm{z}=1095.4$ and $\mathrm{m} / \mathrm{z}=1111.4$, which are indicative of the sodium and potassium adducts of a peptide with the mass of 1072.5 Dalton, and further, by co-elution with synthetic Phymo-AKH-III (Fig. 1A, lower panel). The latter result was absolutely necessary for an unambiguous identification because the mass of 1072.5 Dalton could also point to the peptide Lom-AKH-III, which differs from Phymo-AKH-III in a $\mathrm{Leu}^{2} / \mathrm{Ile}^{2}$ exchange and, thus, also differs by retention time in our HPLC system (Siegert et al., 2000). As the code-name for this peptide implies, it had previously been shown to occur in two other pyrgomorphid grasshoppers, Phymateus morbillosus and Dictyophorus spumans (Siegert et al., 2000).

The structural data by Edman degradation after enzymatic deblocking of the L. sparrmani peak I (retention time of $11.1 \mathrm{~min}$ ) and peak II (retention time of 16.1 min), gave the following results (pmoles in brackets): peak I = Val (25)-Asn (10)-Phe (19)-Ser (8)-Thr (6)-Gly (6)-Trp (2), and peak II = Leu (52)-Asn (31)-Phe (45)-Thr (20)-Pro (19)-Asn (12)-Trp (10). The third peak of $L$. sparrmani with biological activity had the same 


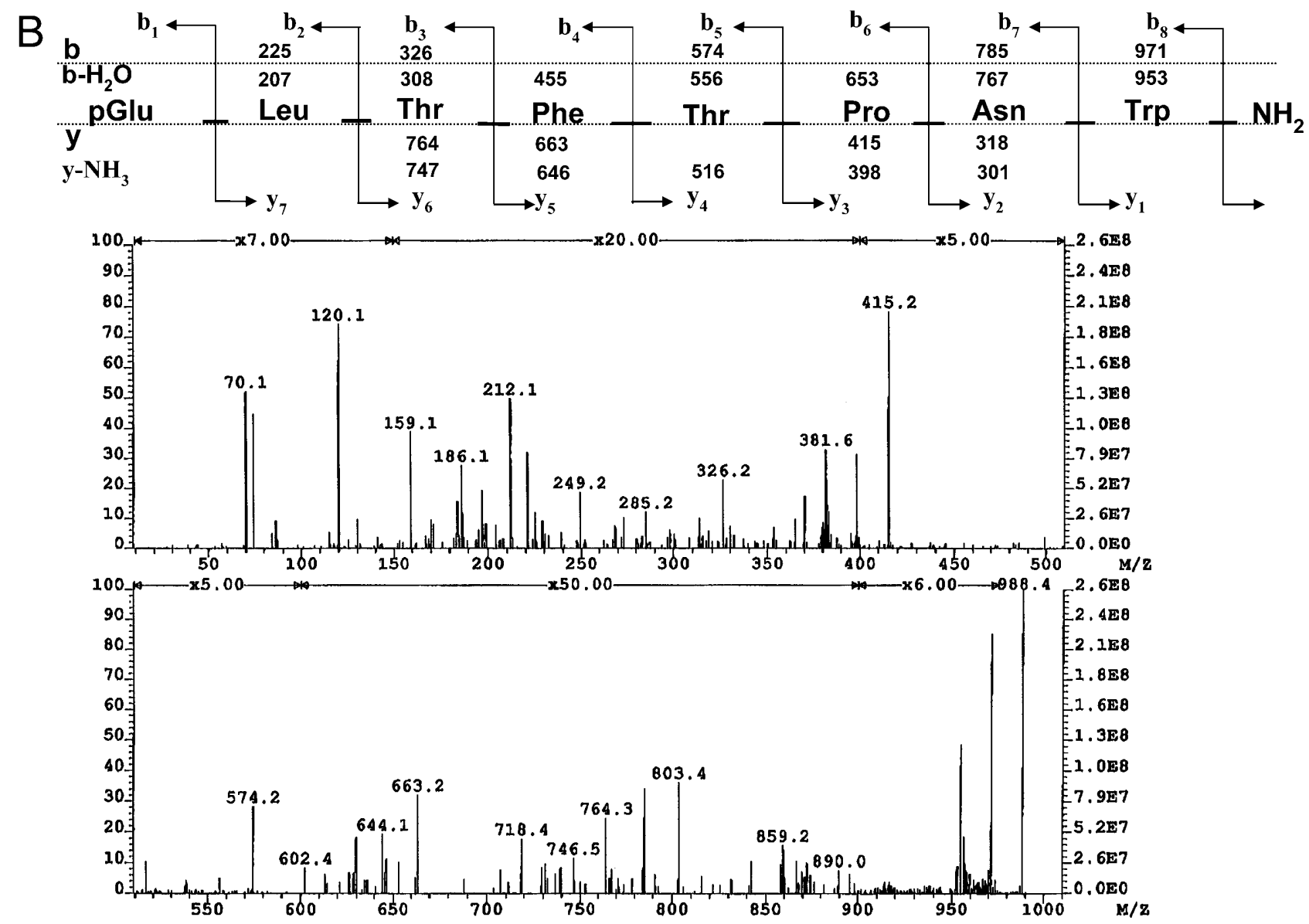

Fig. 2 continued.

retention time (29.8 $\mathrm{min})$ as peak III from $Z$. elegans and, not surprisingly, MALDI-TOF MS $(\mathrm{m} / \mathrm{z}=1095.5$ and $\mathrm{m} / \mathrm{z}$ $=1111.5$ ) and co-elution with Phymo-AKH-III (see Fig. 1B, lower panel) confirmed the identity of this peptide material. At the time of Edman analysis (1996), the peptide identified at retention time of $16.1 \mathrm{~min}$ was a novel member of the AKH family. It is the octapeptide form of the main peptide of the migratory locust, Locmi-AKH-I, thus des-Gly ${ }^{9}, \mathrm{Thr}^{10}$-Locmi-AKH-I and it was code-named Lamsp-AKH in our laboratory in accordance with the species of origin. In 2000, a peptide with the same sequence was discovered as the main $\mathrm{AKH}$ peptide in the $\mathrm{CC}$ of the firebug, Pyrrhocoris apterus, where it is involved in lipid-mobilisation and stimulation of walking activity; today, the peptide is, thus, code-named Pyrap-AKH (Kodrík et al., 2000). The other peptides of L. sparrmani with retention times of $11.1 \mathrm{~min}$ and 29.8 min are well-known members of the AKH family previously elucidated from other species, viz. Grybi-AKH (at $11.1 \mathrm{~min}$ ) is present in the CC of true crickets of the Ensifera, in Neuroptera, Dermaptera and some Hymenoptera (Gäde \& Rinehart, 1987; Gäde, 1992, 1997, 1999; Lorenz et al., 2001; Gäde et al., 2003), and PhymoAKH-III is present in pyrgomorphid grasshoppers (see above). The assignment of the peptides Grybi-AKH and Pyrap-AKH in the CC of L. sparrmani was also con- firmed by co-elution of native and synthetic peptides (see Fig. 1B, lower panel).

The complement of AKH peptides in the two species investigated in this study warrants some comments. First, apparently the more ancestral insect taxa (Odonata, Ephemeroptera) contain only one member of the AKH family in their CC (Gäde \& Marco, 2005) but later during evolution, gene duplication occurred and two AKH peptides are found in some taxa. However, $3 \mathrm{AKH}$ peptides have only been documented thus far in a few species of Caelifera, i.e. L. migratoria (Oudejans et al., 1991), P. morbillosus and D. spumans (Siegert et al., 2000). Here, we demonstrate that other grasshopper species also contain 3; but a complement of $3 \mathrm{AKHs}$ is surely not the rule, because a number of locusts such as $S$. gregaria (Oudejans et al., 1991), Anacridium aegypticum, Nomadacris septemfasciata and Acanthacris ruficornis (G. Gäde, unpubl. results) have only two AKH peptides. Second, all data on locust and grasshopper AKH peptides, to date, show that at least one of the peptides is a decapeptide (Gäde et al., 1997; Siegert et al., 2000). In contrast, the grasshopper species of the present study contain $3 \mathrm{AKH}$ peptides, all of which are octapeptides. The complement of AKHs in these two investigated species is, thus, unusual and unique. Third, it may also be quite illustrative to compare the sequences of the 3 peptides in each of the two investigated species (Table 3). It becomes 
TABLE 3. Comparison of the three AKH peptides found in Z. elegans and L. sparrmani.*

\begin{tabular}{llll}
\hline & L. sparrmani & & Z. elegans \\
\hline Grybi-AKH & pEVNFSTGWamide & Schgr-AKH-II & pELNFSTGWamide \\
Pyrap-AKH & pELNFTPNWamide & Peram-CAH-II & pELTETPNWamide \\
Phymo-AKH-III & pEINFTPWWamide & Phymo-AKH-III & pEINFTPWWamide \\
\hline
\end{tabular}

*The amino acid in bold shows the difference between the respective peptides in the two species.

obvious that both species synthesise AKHs which are very closely related, viz. Grybi-AKH (in L. sparrmani) and Schgr-AKH-II (in Z. elegans) differ only in a $\mathrm{Val}^{2} / \mathrm{Leu}^{2}$ exchange, whereas Pyrap-AKH and Peram$\mathrm{CAH}-\mathrm{II}$ differ in an $\mathrm{Asn}^{3} / \mathrm{Thr}^{3}$ exchange. These changes are conservative and, on the RNA level, can be explained by a single base change in the coding triplet, which leads to a single point mutation in the peptide sequence. Of course, both species contain an identical third AKH, viz. Phymo-AKH-III. In this context it is interesting to note that, on morphological grounds, Caelifera are divided into 7 higher taxa (superfamilies), one of which comprises Pyrgomorphidae and Pamphagidae, i.e. the Pamphagoidea (see Table 1 in Rowell \& Flook, 1998). This relationship was not supported, however, when caeliferan phylogeny was reconstructed using mitochondrial and nuclear ribosomal RNA gene sequences (Rowell \& Flook, 1998): the Pyrgomorphidae were closest placed to the Pneumoridae, and the Pamphagidae were closely grouped to the acridid subfamilies. Our data on AKH sequences of the two species belonging to the Pyrgomorphidae (Z. elegans) and Pamphagidae (L. sparrmani) do not resolve this problem of exact phylogenetic relationship, but clearly indicate that the 3 peptides in each species are very closely related.

As to the possible functions of the 3 peptides in each species, very little can be reported. The conspecific bioassays executed with $Z$. elegans show no effect on the concentration of lipids or carbohydrates in the haemolymph upon injection of 0.1 pair equivalent (Table 2 ). It is only to note that the concentration of carbohydrates is quite high. As in other insects previously, it was established that trehalose was by far the most abundant oligosaccharide present in the haemolymph of $Z$. elegans (results not shown). The very few conspecific tests performed on $L$. sparrmani (Table 2) seem to have indicated that at least one of the endogenous peptides, Pyrap-AKH, causes a slight hypertrehalosaemic effect, which was, however, not significant. These data have to be taken into consideration with caution because only 3 specimens were analysed and no control group was included due to a shortage of insects. Again, it is to note that the concentration of carbohydrates in the haemolymph is very high, even twice as high as found in migratory locusts (Jutsum \& Goldsworthy, 1976). It is, therefore, not unreasonable to conclude that it appears that carbohydrates may play a larger role in energy metabolism in these two grasshopper species than lipid metabolism.

Does the life history of the species give any clues as to whether a mainly carbohydrate- or lipid-based metabolism is used for providing energy? Although there exist winged forms of $Z$. elegans, the specimens used in this study were wingless adults or they had tiny, rudimentary wings. Thus, flight is no option and locomotory activity is mainly comprised of hopping. It has been reported that AKH peptides are involved in stimulation of locomotory activity in P. apterus and Gryllus bimaculatus, respectively (Socha et al., 1999; Lorenz et al., 2004). This may be true for $Z$. elegans as well and carbohydrates are fuelling this activity. This situation appears to be similar to what is known from the romalid grasshopper, Romalea microptera: it does not respond to its endogenous $\mathrm{AKH}$ peptides in the sense of showing a change in the concentrations of metabolites in the haemolymph, although an activation of phosphorylase in the fat body is clearly demonstrated after injection of the endogenous AKH peptides (Gäde \& Spring, 1989).

Since the main effect of AKH peptides in insects that show good flight performance is the mobilisation of lipids (see Gäde, 2004), it was surprising to find no adipokinetic effect of Pyrap-AKH in L. sparrmani, although males of this species have long wings and fly well (own observation). However, another observation may shed some light on the results: calling behaviour of male L. sparrmani was observed only at dusk and dark and with the male remaining stationary in low vegetation. Because the females are wingless and the males remain sedentary during calling, it is deduced that the females are attracted by the songs and walk to the source of the sound to meet the males. Thus, although male L. sparrmani are good flyers, they do not embark on long-distance flights and are mostly sedentary or, at best, engaged in short flights. Again, phosphorylase may be activated by the endogenous AKHs and carbohydrates mobilised to fuel this activity.

In conclusion, two species of different families of grasshoppers have been shown to store three octapeptides of the AKH family of peptides in their CC. It appears that the biological activity of these peptides is somewhat related to carbohydrate metabolism of the grasshoppers.

ACKNOWLEDGEMENTS. The author thanks R. Kellner (Merck KGaA, Darmstadt, Germany) and K.L. Rinehart (University of Illinois, Urbana, IL, USA) for contributing the Edman and FAB-MS sequencing data, respectively, H.G. Marco (University of Cape Town, South Africa) for performing MALDI-TOF MS and for improving the English text, and the National Research Foundation (Pretoria, South Africa; grant number: 2053806) and UCT for financial support.

\section{REFERENCES}

GÄDE G. 1980: Further characteristics of adipokinetic and hyperglycaemic factor(s) of stick insects. J. Insect Physiol. 26: $351-360$. 
GÄDE G. 1985: Isolation of the hypertrehalosaemic factors I and II from the corpus cardiacum of the Indian stick insect, Carausius morosus, by reversed-phase high performance liquid chromatography, and amino-acid-composition of factor II. Biol. Chem. H.-S. 366: 195-199.

GäDE G. 1991a: The adipokinetic neuropeptide of Mantodea. Sequence elucidation and evolutionary relationships. Biol. Chem. H.-S. 372: 193-201.

GäDE G. 1991b: Hyperglycaemia or hypertrehalosaemia - the effect of insect neuropeptides on haemolymph sugars. $J$. Insect Physiol. 37: 483-487.

GÄDE G. 1992: Isolation and structure elucidation of neuropeptides of the AKH/RPCH family in long-horned grasshoppers (Ensifera). Biol. Chem. H.-S. 373: 1169-1178.

GÄDE G. 1996: The revolution in insect neuropeptides illustrated by the adipokinetic hormone/red pigment-concentrating hormone family of peptides. Z. Naturforsch. (C) 51: 607-617.

GäDE G. 1997: Metabolic neuropeptide from the corpus cardiacum of antlions (Neuroptera: Myrmeleontidae): purification and identification. Afr. Entomol. 5: 225-230.

GäDE G. 1999: Presence of an adipokinetic peptide in the corpus cardiacum of Dermaptera but not in the neurohaemal aorta, and chemical and functional identification of the peptide. Physiol. Entomol. 24: 327-332.

GÄDE G. 2004: Regulation of intermediary metabolism and water balance of insects by neuropeptides. Annu. Rev. Entomol. 49: 93-113.

GÄDE G. \& Auerswald L. 1998: Flight metabolism in carpenter bees and primary structure of their hypertrehalosaemic peptide. Exp. Biol. Online 3: 1-12.

GäDE G. \& KelLner R. 1989: The metabolic neuropeptides of the corpus cardiacum from the potato beetle and the American cockroach are identical. Peptides 10: 1287-1289.

GädE G. \& MARCo H.G. 2005: The adipokinetic hormones of Odonata: A phylogenetic approach. J. Insect Physiol. 51: 333-341.

Gäde G. \& Rinehart K.L. 1987: Primary sequence analysis by fast atom bombardment mass spectrometry of a peptide with adipokinetic activity from the corpora cardiaca of the cricket Gryllus bimaculatus. Biochem. Bioph. Res. Co. 149: 908-914.

GädE G. \& Rinehart K.L. 1990: Primary structures of hypertrehalosaemic neuropeptides isolated from the corpora cardiaca of the cockroaches Leucophaea maderae, Gromphadorhina portentosa, Blattella germanica and Blatta orientalis and of the stick insect Extatosoma tiaratum assigned by tandem fast atom bombardment mass spectrometry. Biol. Chem. H.-S. 371: 345-354.

GäDE G. \& SPRING J.H. 1989: Activation of fat body glycogen phosphorylase in the Eastern lubber grasshopper (Romalea microptera) by the endogenous neuropeptides Ro-I and Ro-II. J. Exp. Zool. 250: 140-149.

Gäde G., Goldsworthy G.J., Kegel G. \& Keller R. 1984: Single step purification of locust adipokinetic hormones I and II by reversed-phase high-performance liquid chromatography, and the amino-acid-composition of the hormone II. H.-S. Z. Physiol. Chem. 365: 393-398.

Gäde G., Goldsworthy G.J., Schaffer M.H., Cook J.C. \& RineHART K.L. 1986: Sequence analyses of adipokinetic hormones II from corpora cardiaca of Schistocerca nitans, Schistocerca gregaria, and Locusta migratoria by fast atom bombardment mass spectrometry. Biochem. Bioph. Res. Co. 134: 723-730.

Gäde G., Hilbich C., Beyreuther K. \& Rinehart K.L. 1988: Sequence analyses of two neuropeptides of the AKH/RPCHfamily from the lubber grasshopper, Romalea microptera. Peptides 9: 681-688.
Gäde G., Kellner R. \& Rinehart K.L. 1996: Pyrgomorphid grasshoppers of the genus Phymateus contain species-specific decapeptides of the AKH/RPCH family regulating lipidmobilization during flight. Physiol. Entomol. 21: 193-202.

GÄDE G., HofFmanN K.H. \& SpRING J.H. 1997: Hormonal regulation in insects: Facts, gaps, and future directions. Physiol. Rev. 77: 963-1032.

Gäde G., Marco H.G. \& Desutter-Grandcolas L. 2003: A phylogenetic analysis of the adipokinetic neuropeptides of Ensifera. Physiol. Entomol. 28: 283-289.

Jutsum A.R. \& Goldsworthy G.J. 1976: Fuels for flight in Locusta. J. Insect Physiol. 22: 243-249.

Kodrík D., Socha R., Šimek P., Zemek R. \& Goldsworthy G.J. 2000: A new member of the AKH/RPCH family that stimulates locomotory activity in the firebug, Pyrrhocoris apterus (Heteroptera). Insect Biochem. Molec. Biol. 30: 489-498.

KodRíK D., ŠIMEK P., LePŠA L. \& SochA R. 2002: Identification of the cockroach neuropeptide Pea-CAH-II as a second adipokinetic hormone in the firebug Pyrrhocoris apterus. Peptides 23: 585-587.

Lorenz M.W., Kellner R., Völkl W., Hoffmann K.H. \& Woodring J. 2001: A comparative study on hypertrehalosaemic hormones in the Hymenoptera: sequence determination, physiological actions and biological significance. J. Insect Physiol. 47: 563-571.

Lorenz M.W., Zemek R., Kodrík, D. \& Socha R. 2004: Lipid mobilization and locomotor stimulation in Gryllus bimaculatus by topically applied adipokinetic hormone. Physiol. Entomol. 29: 146-151.

Oudejans R.C.H.M., Kooiman F.P., Heerma W., Versluis C., Slotboom A.J. \& BeEnaKKers A.M.T. 1991: Isolation and structure elucidation of a novel adipokinetic hormone (LomAKH-III) from the glandular lobes of the corpus cardiacum of the migratory locust, Locusta migratoria. Eur. J. Biochem. 195: 351-359.

Rowell C.H.F. \& Flook P.K. 1998: Phylogeny of the Caelifera and the Orthoptera as derived from ribosomal gene sequences. J. Orthopt. Res. 7: 147-156.

Scarborough R.M., Jamieson G.C., Kalish F., Kramer S.J., McEnroe G.A., Miller C.A. \& Schooley D.A. 1984: Isolation and primary structure of two peptides with cardioacceleratory and hyperglycemic activity from the corpora cardiaca of Periplaneta americana. Proc. Natl Acad. Sci. (Biol.) 81: 5575-5579.

Siegert K., Morgan P. \& Mordue W. 1985: Primary structures of locust adipokinetic hormones II. Biol. Chem. H.-S. 366: 723-727.

Siegert K.J., Kellner R. \& Gäde G. 2000: A third active AKH is present in the pyrgomorphid grasshoppers Phymateus morbillosus and Dictyophorus spumans. Insect Biochem. Molec. Biol. 30: 1061-1067.

Socha R., Kodrík D. \& Zemek R. 1999: Adipokinetic hormone stimulates insect locomotor activity. Naturwissenschaften $\mathbf{8 6}$ : 85-86.

SpiK G. \& Montreuil J. 1964: Deux causes d'erreur dans les dosages colorimetriques des oses neutres totaux. Bull. Soc. Chim. Biol. 46: 739-749.

Stone J.V., Mordue W., Batley K.E. \& Morris H.R. 1976: Structure of locust adipokinetic hormone, a neurohormone that regulates lipid utilization during flight. Nature 263: 207-211.

Witten J.L., Schaffer M.H., O’Shea M., Cook J.C., Hemling M.E. \& RineHART K.L. 1984: Structures of two cockroach neuropeptides assigned by fast atom bombardment mass spectrometry. Biochem. Bioph. Res. Co. 124: 350-358. 
ZöLlNER N. \& KIRSCH K. 1962: Über die quantitative Bestimmung von Lipoiden (Mikromethode) mittels der vielen natürlichen Lipoiden (allen bekannten Plasmalipoiden) gemein- samen Sulfophosphovanillin Reaktion. Z. Ges. Exp. Med. 135: 545-561.

Received August 30, 2005; revised and accepted December 1, 2005 